\title{
ROLAND BARTHES NO BRASIL, VIA TRADUÇÕES
}

\author{
Laura Taddei Brandini \\ Universidade Estadual de Londrina
}

\begin{abstract}
Resumo: Este artigo tematiza a recepção à obra de Roland Barthes no Brasil pelo viés das traduções de seus livros e ensaios. Mais especificamente, reconstitui-se a história das traduções de Barthes em suas relações com os cenários intelectuais brasileiros mais significativos para sua obra, os dos anos 70 e 2000, à luz da Teoria do Polissistema Literário, de Itamar Even-Zohar: no primeiro momento, foram traduzidas as obras do escritor francês que melhor correspondiam ao anseio dos intelectuais brasileiros por teorias de origem linguística, versáteis o bastante para servir como fundamentação analítica para a leitura dos mais variados objetos; no segundo momento, o interesse por Barthes encontrou na canonização que a pós-modernidade lhe infringiu a justificativa para uma revisão de sua obra. Tanto no primeiro como no segundo momento, as traduções dos textos barthesianos refletem imagens diferentes do escritor francês, construídas pelos intelectuais brasileiros, que evidenciam as particularidades de cada um desses momentos histórico-culturais.
\end{abstract}

Palavras-chave: Roland Barthes. Estudos de Recepção. Tradução. Crítica.

\footnotetext{
* Laura Taddei Brandini possui graduação e mestrado em Letras pela Universidade de São Paulo e obteve um Diplôme d'Etudes Approfondies em literatura francesa pela Universidade de Genebra, Suíça. Doutorou-se pelas duas universidades, em co-tutela, com tese sobre as relações Brasil-França e atualmente faz pós-doutorado em literatura comparada na Universidade de Paris IV - Sorbonne, Paris. E Professora Adjunta no Departamento de Letras Estrangeiras Modernas da Universidade Estadual de Londrina, Londrina, Paraná, Brasil. E-mail: laura@uel.br
} 


\title{
ROLAND BARTHES IN BRAZIL, BY TRANSLATIONS
}

\begin{abstract}
This article studies the reception to the work of Roland Barthes in Brazil by the translations of his books and essays. More specifically, and according to the Theory of Literary Polisystem, by Itamar Even- Zohar, it retraces the history of the translations of Barthes in its relations with the most important Brazilian intellectuals scenarios for his work, the '70s and 2000s: at first the works of the French writer that best corresponded to the desire of Brazilian intellectuals by theories came from linguistic studies, versatile enough to serve as an analytical basis for reading the most varied objects, were translated; in the second time, interest in Barthes found in the canonization imposed by the postmodernity thought his justification for a review of his work. Both in the first and the second moment, the translations of barthesians texts reflect different images of the French writer, built by Brazilian intellectuals, which show the characteristics of each of these historic cultural moments.
\end{abstract}

Keywords: Roland Barthes. Reception Studies. Translation. Criticism.

Roland Barthes nunca colocou os pés no Brasil. Embora tenha sido convidado por Leyla Perrone-Moisés a ministrar conferências em universidades brasileiras e, por carta, eles tenham até mesmo discutido detalhes dessa empreitada (Perrone-Moisés, 2012), a viagem nunca se concretizou. No entanto, por meio da tradução de suas obras, Barthes frequenta os meios intelectuais brasileiros desde 1970, quando Critique et Vérité (1966) e uma seleção dos Essais critiques (1964) foram traduzidos pela mesma Leyla Perrone-Moisés e publicados com o título de Crítica e verdade. Desde então, a presença barthesiana no Brasil tem sido constante, apesar de heterogênea: a escolha das obras traduzidas acaba refletindo necessidades específicas do contexto cultural brasileiro, que mudam segundo o momento da história intelectual do país. Este artigo tem como meta estabelecer conexões entre o pensamento crítico barthesiano e a atividade tradutória para, em seguida, apresentar dados sobre a história das traduções das obras de Barthes no Brasil, relacionando-a com o sistema literário brasileiro.

Barthes nunca traduziu uma única obra. Não era um grande conhecedor de idiomas ${ }^{1} \mathrm{e}$ pouco se interessou por questões relativas 
à tradução, o que ele mesmo explica em fragmento sobre a língua materna, em Roland Barthes por Roland Barthes (1975): “(...) pouco gosto pelas literaturas estrangeiras, pessimismo constante com relação à tradução, aflição diante das perguntas dos tradutores, de tal forma eles parecem ignorar frequentemente o que eu penso ser o próprio sentido de uma palavra: a conotação" (2003, p. 132). O escritor certamente se referia ao sentido mais restrito da tradução, à puramente utilitária, que não respeita a polissemia $\mathrm{e}$ que é, portanto, uma redução do texto-fonte.

Apesar dessa opinião negativa, em algumas de suas reflexões sobre a crítica literária, Barthes manifestou posições que se aproximam de certos conceitos modernos de tradução. Em "O que é a crítica?", célebre artigo de 1963 publicado primeiramente na Times Literary Supplement e, na França, nos Ensaios críticos, Barthes define a crítica literária como uma metalinguagem, nos seguintes termos: "a crítica é discurso sobre um discurso; é uma linguagem segunda ou metalinguagem (como diriam os lógicos), que se exerce sobre uma linguagem primeira (ou linguagem-objeto)" (1970, p. 160). Mais adiante, colocando em questão a ideia de que a crítica tem a palavra final sobre a obra - à época, muito cara aos críticos tradicionais -, tendo em vista, como exemplo, Em Busca do tempo perdido, de Proust, Barthes explica que

seu papel [da crítica] é unicamente elaborar ela mesma uma linguagem cuja coerência, cuja lógica, e para dizer tudo, cuja sistemática possa recolher, ou melhor ainda, "integrar" (no sentido matemático da palavra) a maior quantidade possível de linguagem proustiana, exatamente como uma equação lógica experimenta a validade de um raciocínio sem tomar partido quanto à "verdade" dos argumentos que ele mobiliza. (Ibid., p. 161)

Ou seja, a crítica deve se constituir como uma linguagem segunda que "integra" a linguagem da obra literária, tal como um 
marceneiro encaixa duas partes de um móvel, fazendo, para tanto, os ajustes necessários, segundo a comparação de Barthes. O crítico, então, "ajusta" "a linguagem que lhe fornece sua época (existencialismo, marxismo, psicanálise) à linguagem, isto é, ao sistema formal de constrangimentos lógicos elaborados pelo próprio autor segundo sua própria época" (Ibidem). Ou seja, Barthes vê a atividade crítica como a elaboração de uma linguagem no sentido pleno do termo, o de escrita literária ou, na concepção barthesiana, escritura: ancorada no presente do crítico que, contudo, mantém uma relação estreita com a linguagem da obra literária; esta, ligada a seu tempo mas nunca a ele confinada, pois prenhe de sentidos em devir ${ }^{2}$.

Tal compreensão da crítica pode ser aproximada da teoria da tradução de Haroldo de Campos. Em A Operação do texto o poeta concretista e tradutor relembra seus primeiros passos traduzindo Maiakóvski. Apesar de seus parcos conhecimentos do idioma russo na época, mostra como obteve êxito porque "tinha também presente o problema específico da tradução de poesia, que, a meu [seu] ver, é modalidade que se inclui na categoria da criação. Traduzir poesia há de ser criar, sob pena de esterilização e petrificação, o que é pior do que a alternativa de trair" (apud Schnaiderman, 2003a, p. 61). O conceito de transcriação é central na poética da tradução de Campos ${ }^{3}$ e reúne as ideias de criação e de transposição de linguagens, as molas-motoras da escrita literária e da tradução, respectivamente. Para ele, traduzir uma obra significa recriá-la, ou transcriá-la, criar uma nova obra a partir da transposição de sua linguagem para uma outra língua:

Tudo isto o tradutor tem que transcriar, excedendo os lindes de sua língua, estranhando-lhe o léxico, recompensando a perda aqui com uma intromissão inventiva acolá, a infratradução forçada com a hipertradução venturosa, até que o desatine e desapodere aquela última Húbris (culpa luciferina, transgressão semiológica?), que é transformar o original na tradução de sua tradução. (apud Schnaiderman, 2003b, p. 179) 
Quando o original se torna a "tradução de sua tradução", rompe-se a hierarquia entre a obra literária e sua tradução, prevalecendo unicamente a relação de precedência, sem que, no entanto, ela implique em uma ordem de valores. Ora, também uma quebra de paradigma - a supremacia da obra literária sobre o texto crítico - é o que propõe Barthes. E Campos, grande leitor do escritor francês desde os anos 1960, com base nas teorias de Max Bense e Ezra Pound, estabelece a conexão entre tradução e crítica: nessa mesma década, os poetas concretistas, pretendendo estrategicamente preparar o sistema literário brasileiro para seus poemas então revolucionários, dedicaram-se a uma intensa atividade tradutória, naturalmente escolhendo as obras estrangeiras que corroboravam suas convicções e contribuíam para o desenvolvimento de suas reflexões sobre a literatura: "Fazendo-o, tinham presente justamente a didática decorrente da teoria e da prática poundiana da tradução e suas ideias quanto à função da crítica - e da crítica via tradução - como 'nutrimento do impulso' criador" (Campos, 1992, p. 42).

Embora Barthes não seja citado no trecho acima - e sim Ezra Pound, outro grande pensador da linguagem -, a compreensão da crítica enquanto alimento da criação literária a aproxima da definição da crítica como escritura, da crítica enquanto Texto. Contudo, em Crítica e verdade, tratando da definição de crítica, Barthes afirma: "Quando um crítico tira do pássaro e do leque malarmeanos um 'sentido' comum, o do ir e vir, do virtual, não está designando uma última verdade da imagem, mas somente uma nova imagem, ela própria suspensa. A crítica não é uma tradução, mas uma perífrase" (1970, p. 226). Nesse trecho, Barthes repudia a comparação entre crítica e tradução porque se refere a esta como a transposição final e única de uma palavra ou expressão para outro sistema linguístico, o que revela uma concepção limitada da atividade tradutória. A tradução pode e, em muitos casos, deve ser perífrase e, portanto, implica em uma interpretação, uma leitura pessoal, como já explicava Jakobson em "Aspectos linguísticos da tradução": 
A tradução intralingual de uma palavra utiliza outra palavra, mais ou menos sinônima, ou recorre a um circunlóquio. (...) Da mesma forma, na tradução interlingual, não há comumente equivalência completa entre as unidades de código, ao passo que as mensagens podem servir como interpretações adequadas das unidades de código ou mensagens estrangeiras. (...) Mais frequentemente, entretanto, ao traduzir de uma língua para outra, substituem-se mensagens em uma das línguas, não por unidades de código separadas, mas por mensagens inteiras de outra língua. Tal tradução é uma forma de discurso indireto: o tradutor recodifica e transmite uma mensagem recebida de outra fonte. Assim, a tradução envolve duas mensagens equivalentes em dois códigos diferentes. (1995, p. 65)

Portanto, apesar do discurso oposto, Barthes, em sua teoria e prática da crítica aproxima-se do conceito de tradução de Campos, pois esta, entendida como uma atividade criadora e crítica ao mesmo tempo, permite que os três conceitos - texto literário, crítica e tradução - se imbriquem.

De uma maneira explícita, é Tania Carvalhal quem faz a ponte entre Barthes e a tradução, em seu ensaio “Tradução e recepção na prática comparatista”, citando um trecho de $S / Z$ (1970):

\footnotetext{
"Há, de um lado, o que é possível escrever e, de outro, o que não é mais possível escrever: o que é na prática do escritor e no que dela decorre: que textos aceitaria eu escrever (reescrever), desejar, lançar como uma força neste mundo que é o meu?"

Retomando e transformando as palavras finais do autor, diríamos: "que textos aceitaria eu traduzir para lançá-los como uma força neste mundo que é o meu?" (Carvalhal, 2003, p. 247)
}

Tanto no verbo escrever, para Barthes, quanto em traduzir, para Tania Carvalhal, estão compreendidos dois movimentos inse- 
paráveis: a criação, ou recriação, ou transcriação, trabalho desenvolvido no interior da linguagem, movido pelo desejo do autor e/ ou tradutor; e a sua disseminação.

As traduções, lançadas "como uma força” num sistema literário, interferem em seu funcionamento, introduzindo novos conceitos ou ratificando ideias vigentes. Acerca desse fenômeno Itamar Even-Zohar desenvolveu fecundas reflexões concebendo sua Teoria do Polissistema Literário. Para esse autor, as traduções não podem ser vistas fora de um sistema cultural, como ele explica:

\begin{abstract}
My argument is that translated works do correlate in at least two ways: (a) in the way their source texts are selected by the target literature, the principles of selection never being uncorrelatable with the home co-systems of the target literature (to put it in the most cautious way); and (b) in the way they adopt specific norms, behaviors, and policies - in short, in their use of the literary repertoire - which results from their relations with the other home co-systems. (2000, p. 192-193)
\end{abstract}

Essa concepção dinâmica das relações entre traduções e sistemas literários mostra-se bastante útil para a leitura da recepção à obra de Barthes no Brasil pelo viés de suas traduções. Por um lado, a voga dos estudos linguísticos e sociológicos dos anos 1960 e 1970, alimentada pela consolidação das instituições universitárias, fez com que se procurasse no exterior bibliografia então quase inexistente no país. Nesse contexto, destacam-se as editoras paulistas Cultrix e Perspectiva, graças à grande quantidade de títulos publicados nas áreas citadas, a maioria composta por traduções de obras estrangeiras, francesas e estadunidenses, sobretudo. As obras traduzidas - inclusive os livros de Barthes e diversas coletâneas que contém artigos do escritor - eram selecionadas segundo as necessidades locais, em acordo com o item "a” da argumentação de Even-Zohar.

Por outro lado, as teorias e concepções que desembarcavam por meio dessas traduções traziam ao Brasil questões e maneiras de 
encarar problemas próprias às realidades dos países estrangeiros, muitas vezes resultando em um choque entre culturas: ideias longamente amadurecidas em um contexto universitário diversificado e antigo, como os da Europa, aportavam repentinamente no ainda acanhado ambiente intelectual brasileiro. Essa diferença de percepção se deu, por exemplo, com O grau zero da escritura (1953), primeiro livro de Barthes, cuja recepção inicial foi bastante negativa no Brasil e positiva na França. Barthes foi lido pelos críticos brasileiros dos anos 50 como um jovem intelectual mais preocupado em criar jogos de palavras do que em contribuir efetivamente para a construção de uma ideia de literatura, sendo, portanto, totalmente desinteressante aos olhos da crítica que ainda buscava estabelecer as bases teóricas para a construção de uma literatura nacional (Milliet, 1953, p. 6). Em outras palavras, as traduções fornecem ao sistema de chegada um arcabouço de questões e significados próprio a seu sistema de origem, passíveis de gerar controvérsia e incompreensão dentro do sistema de chegada, como Even-Zohar descreve no item " $b$ " do trecho citado.

A fim de visualizar as relações entre as traduções dos livros de Barthes e os diferentes momentos do sistema literário brasileiro, organizei cronologicamente as obras publicadas em primeira edição na França e suas traduções no Brasil numa listagem que apresento ao final do artigo.

Da listagem destaco dois momentos na história das traduções de Barthes no Brasil: as décadas de 1970 e de 2000. Nos anos 70 , foram traduzidos predominantemente os livros de Barthes que melhor respondiam à necessidade de bibliografia sobre linguística aplicada à leitura do texto literário, de que o sistema brasileiro carecia, conforme já mencionei. Foram publicados, no período: Crítica e verdade seguido de coletânea dos Ensaios críticos (1970), O grau zero da escritura (1971), Elementos de semiologia (1971), Análise estrutural da narrativa (1971), Mitologias (1972), Novos ensaios críticos seguidos de O grau zero da escritura (1974), Sistema da Moda (1979) e O que é a literatura (entrevista com Barthes) (1979). Além dessas obras, que correspondiam à visada linguística 
nos estudos literários, também foram traduzidos $O$ Prazer do texto (1977), Roland Barthes por Roland Barthes (1977) e Aula (1978), já pertencentes à última fase do escritor, mais distante das questões estruturalistas.

Além da clara predominância das editoras Perspectiva (duas traduções) e Cultrix (cinco traduções) na publicação dos livros de Barthes na década, saliento também o papel fundamental de Leyla Perrone-Moisés, tradutora da primeira obra de Barthes no Brasil, Crítica e verdade e da seleção dos Ensaios críticos, bem como de Roland Barthes por Roland Barthes e de Aula. Seu trabalho de divulgação das ideias do escritor, além de pioneiro, estendeu-se pelos anos que se seguiram, tanto nos jornais quanto na universidade e junto a editoras, não se limitando aos anos 70.

Na primeira década do século XXI identifico um novo momento em que as obras de Barthes foram traduzidas em grande número. O interesse de muitos de seus conceitos foi reconhecido pela pós-modernidade (considerada aqui como datando de 1990 até hoje), que revitalizou seus escritos publicados a partir do Prazer do texto, como a produção acadêmica atual evidencia. No entanto, nesse momento, as obras barthesianas saíram por várias editoras diferentes, muitas delas tendo demorado para serem traduzidas, como $\mathrm{Mi}$ chelet e $O$ Império dos signos, que esperaram por nada menos do que 37 anos, dentre outros casos menos gritantes mas igualmente escandalosos. A inconstância das reedições de obras já traduzidas e o longo tempo para se traduzir obras inéditas no Brasil fizeram com que durante aproximadamente 20 anos o acesso aos livros de Barthes ficasse bastante difícil, muitas vezes restrito às caras edições portuguesas das Edições 70, ao passo que a demanda por seus escritos recebia novo impulso por parte dos estudos chamados pós-modernos. Exceções pipocaram aqui e ali, como a publicação de Fragmentos de um discurso amoroso (1981), verdadeiro best seller que engendrou até mesmo a criação de uma peça teatral de sucesso (prêmio Molière de melhor ator para Antônio Fagundes), de $A$ Câmara clara (1984) e da coletânea O Rumor da língua (1988), contendo o famoso ensaio "A Morte do autor". Essas obras, intro- 
duzidas no sistema literário brasileiro num período de transição, prepararam o terreno para a nova imagem de Barthes, a se firmar nas décadas seguintes.

Mais uma vez, uma necessidade do sistema literário alavancou a presença de Barthes no mercado editorial brasileiro: a Editora Martins Fontes, desde 2005 WMF Martins Fontes ${ }^{4}$, criou, em 2000, a Coleção Roland Barthes, cuja direção está a cargo de Leyla Perrone-Moisés. Portanto, mais uma vez, a trajetória dessa grande intelectual se mistura à história de Barthes, divulgando seus escritos ao público brasileiro. Foram publicados na coleção, até o presente momento, entre novas traduções e inéditos, os seguintes livros: $O$ Grau zero da escrita seguido de Novos ensaios críticos (2000), A Aventura semiológica (2001), Como viver junto. Simulações romanescas de alguns espaços cotidianos. Cursos e seminários no Collège de France 1976-1977 (2003), O Neutro. Anotações de aulas e seminários ministrados no Collège de France 1977-1978 (2003), Fragmentos de um discurso amoroso (2003), O Grão da voz. Entrevistas (1962-1980) (2004), O Rumor da língua (2004), Incidentes (2004), Inéditos, I: teoria (2004), Inéditos, II: crítica (2004), Inéditos, III: imagem e moda (2005), Inéditos, IV: política (2005), A Preparação do romance I - Da Vida à obra. Notas de cursos e seminários no Collège de France, 1978-1979 (2005) $A$ Preparação do romance II - A obra como Vontade. Notas de curso no Collège de France 1979-1980 (2005), Sade, Fourier, Loyola (2005), O Império dos signos (2007), Escritos sobre teatro (2007), Sobre Racine (2008), Sistema da moda (2009), Diário de luto. 26 de outubro de 1977-15 de setembro de 1979 (2011), Cadernos da viagem à China (2012).

O interesse renovado pelas ideias de Barthes nos anos 2000 e o novo influxo de edições lançadas no mercado pela Martins Fontes contagiou outras editoras detentoras dos direitos de publicação das traduções de alguns de seus livros a reeditarem-nos ou até mesmo a se iniciarem nesse "novo" filão. Exemplo disso foi a edição de Roland Barthes por Roland Barthes, traduzido por Leyla Perrone-Moisés para a editora Cultrix em 1977, pela editora Estação Li- 
berdade, em 2003. Ou as reedições de $A$ Câmara clara pela Nova Fronteira (2000), Mitologias pela Difel (2003 e 2009, esta última, pela primeira vez uma edição completa, as anteriores tendo se limitado a uma coletânea das mitologias de 1957), Análise estrutural da narrativa pela Vozes (2008), O Prazer do texto e Crítica e verdade seguido de coletânea dos Ensaios críticos pela Perspectiva (2008 e 2009, respectivamente).

A dinâmica das traduções das obras de Barthes permite definir algumas das imagens dele criadas, segundo as quais o escritor foi lido no Brasil: primeiramente, nos anos 70, foi sobretudo o autor estruturalista que interessou aos intelectuais brasileiros, graças a suas reflexões sobre a linguagem, calcadas nas teorias linguísticas em voga. Elementos de semiologia e o ensaio "Introduction à l'analyse structurale des récits", publicado no Brasil em volume como Análise estrutural das narrativas transformaram-se nas leituras obrigatórias ao intelectual interessado em analisar qualquer tipo de linguagem, da literatura ao cinema, do mobiliário às revistas em quadrinhos, da moda à publicidade, da fotografia ao discurso jornalístico. O Roland Barthes que ora transparecia era o semiólogo, líder do estruturalismo francês, instrumental analítico, pau para toda obra, teoria para toda pesquisa.

No período que se seguiu, longo de aproximadamente vinte anos, esses escritos pareceram datados em demasia e Barthes não mais era procurado com tanto interesse. Mas a pós-modernidade do final dos anos 90 e do início dos anos 2000 ressuscitou o escritor como um todo, reconhecendo nele um precursor de modelos libertários de construção literária: a estética do fragmento e a escrita corpórea, que opera guiada pelo desejo, por exemplo, foram celebradas como formas de ruptura com o padrão de escrita acadêmica, em princípio objetiva e fundamentada em uma lógica puramente racional. Livros como O Prazer do texto, Roland Barthes por Roland Barthes e Fragmentos de um discurso amoroso alçaram Barthes à categoria de figura tutelar subvertora dos paradigmas e inspiram até nossos dias a renovação do ensaio acadêmico, estimulando a inserção da subjetividade através da afirmação do desejo do eu do 
scriptor nesse gênero textual. Nesta última década, além do teor de suas obras, os escritos barthesianos devem muito - novamente - ao trabalho obstinado de uma intelectual, Leyla Perrone-Moisés, sem o qual talvez o reconhecimento tardasse a chegar no Brasil. As traduções e os relançamentos das obras de Barthes que ora frequentam os catálogos das editoras brasileiras dão novo fôlego para que suas obras e ideias frutifiquem muito além do território francês.

\section{Notas}

1. Embora admitisse um certo gosto por línguas bastante diferentes do francês, como, por exemplo, o japonês, cuja estrutura lhe representava o outro. Cf. Barthes, 2003, p. 132.

2. A pluralidade de sentidos do texto literário é fortemente reivindicada por Barthes como argumento contrário à "verdade única" da obra defendida pela velha crítica francesa ao longo do século XX. Cf. "As duas críticas", "O que é a crítica?" e Crítica e verdade (Barthes, 1970).

3. Haroldo de Campos fundamenta sua teoria na tradução de poesia. Porém, não há nada que impeça que ela seja compreendida num sentido mais largo, como uma teoria da tradução literária, da maneira que eu a interpreto.

4. A editora nasceu da Livraria Martins Fontes, esta, empresa familiar fundada em Santos (SP), em 1960. Vinte anos mais tarde, em São Paulo, firmou-se enquanto livraria e também se tornou uma referência no mercado editorial brasileiro por suas publicações de relevância. 


\section{Referências}

BARTHES, Roland. EEuvres complètes. Nouvelle édition revue, corrigée et présentée par Éric Marty. Paris : Éditions du Seuil, 2002. 5v.

. Crítica e verdade. Tradução de Leyla Perrone-Moisés. São Paulo: Editora Perspectiva, 1970.

. Roland Barthes por Roland Barthes. Tradução de Leyla Perrone-Moisés. São Paulo: Estação Liberdade, 2003.

CAMPOS, Haroldo de. Da Tradução como criação e como crítica. In: Metalinguagem \& outras metas. Ensaios de teoria e crítica literária. São Paulo: Editora Perspectiva, 1992. p. 31-48.

CARVALHAL, Tania Franco. O Próprio e o alheio. Ensaios de literatura comparada. São Leopoldo (RS): Editora da Universidade do Vale do Rio dos Sinos, 2003.

EVEN-ZOHAR, Itamar. The Position of translated literature within the literary polysystem. In: Lawrence Venuti (Org.), The Translation Studies Reader. Londres: Routledge, 2000. p. 192-197.

JAKOBSON, Roman. Aspectos linguísticos da tradução. In: Linguística e comunicação. Tradução de Izidoro Blikstein e José Paulo Paes. São Paulo: Cultrix, 1995 [1969]. p. 63-72.

MILLIET, Sérgio. O Grau zero da escrita. In: O Estado de S. Paulo, São Paulo, 17 nov. 1953. p. 6.

PERRONE-MOISÉS, Leyla. Roland Barthes, o saber com sabor. São Paulo: Editora Brasiliense, 1985 [1983].

. Texto, crítica, escritura. São Paulo: Martins Fontes, 2005. 
SCHNAIDERMAN, Boris. Haroldo de Campos e a transcriação da poesia russa moderna. Fragmentos, Florianópolis, , n 25, julho-dezembro, p. 61-68, de 2003. (2003a )

. Haroldo de Campos, poesia russa moderna, transcriação. Revista USP, São Paulo, no 59, p. 172-180, setembro-novembro de 2003. (2003b).

NOVA, Vera Casa; GLENADEL, Paula (Org.). Viver com Barthes. Rio de Janeiro: 7Letras, 2005.

Recebido: 14-02-14

Aceito: 21-05-14 


\section{ANEXO}

\section{Obras de Barthes e suas traduções no Brasil}

(em negrito, as primeiras edições francesas e, em seguida, as traduções brasileiras)

Le Degré zéro de l'écriture. Paris : Éditions du Seuil, 1953.

Le Degré zéro de l'écriture suivi de Éléments de sémiologie. Paris : Gonthier, 1965.

O grau zero da escritura. Tradução de Anne Arnichand e Álvaro Lorencini. São Paulo: Cultrix, 1971.

Elementos de semiologia. Tradução de Izidoro Blikstein. São Paulo: Cultrix/ Editora da Universidade de São Paulo, 1971.

Le Degré zéro de l'écriture suivi de Nouveaux essais critiques. Paris: Éditions du Seuil, 1972.

Novos Ensaios críticos seguidos de $O$ Grau zero da escritura. Tradução de Heloysa de Lima Dantas, Anne Arnichand e Álvaro Lorencini. São Paulo: Cultrix, 1974.

O Grau zero da escrita seguido de Novos ensaios críticos. Tradução de Mário Laranjeira. São Paulo: Martins Fontes, 2000.

Michelet. Paris: Éditions du Seuil, 1954. 
Michelet. Tradução de Paulo Neves. São Paulo: Companhia das Letras, 1991.

Mythologies. Paris : Éditions du Seuil, 1970 (1957).

Mitologias. Tradução de Rita Buongermino e Pedro de Souza. São Paulo: Difusão Europeia do Livro, 1972.

Mitologias. Tradução de Rita Buongermino, Pedro de Souza e Rejane Janowitzer. Rio de Janeiro: Difusão Europeia do Livro, 2009.

Sur Racine. Paris : Éditions du Seuil, 1979 (1963).

Sobre Racine. Tradução de Antonio Carlos Viana. Porto Alegre: L\&PM Editores, 1987.

Sobre Racine. Tradução de Ivone Castilho Benedetti, revisão da tradução de Márcia Valéria Martinez de Aguiar. São Paulo : WMF Martins Fontes, 2008.

La Tour Eiffel. Paris : Delpire Éditeur, 1964.

Essais critiques. Paris : Éditions du Seuil, 1981 (1964).

Critique et vérité. Paris : Éditions du Seuil, 1999 (1966).

Crítica e verdade. Tradução de Leyla Perrone-Moisés. São Paulo : Editora Perspectiva, 1970 (com coletânea dos Essais critiques).

"Introduction à l'analyse structurale des récits". In Communications $\mathrm{n}^{\circ} 8,1966$. 
Análise estrutural da narrativa (seleção de ensaios da revista Communications $\mathrm{n}^{\circ} 8$, 1966). Tradução de Maria Zélia Barbosa Pinto. Rio de Janeiro: Editora Vozes, 1971.

Système de la mode. Paris : Éditions du Seuil, 1983 (1967).

Sistema da moda. Tradução de Lineide do Lago Salvador Mosca, revisão e supervisão Isaac Nicolau Salum. São Paulo: Nacional/ Editora da Universidade de São Paulo, 1979.

Sistema da moda. Tradução de Ivone Castilho Benedetti. São Paulo: WMF Martins Fontes, 2009.

S/Z. Paris : Éditions du Seuil, 1976 (1970).

S/Z. Uma análise da novela Sarrasine de Honoré de Balzac. Tradução de Léa Novaes. Rio de Janeiro: Nova Fronteira, 1992.

L'Empire des signes. Paris : Éditions du Seuil, 2005 (Genebra : A. Skira, 1970).

O Império dos signos. Tradução de Leyla Perrone-Moisés. São Paulo : WMF Martins Fontes, 2007.

Sade, Fourier, Loyola. Paris : Éditions du Seuil, 1980 (1971).

Sade, Fourier, Loyola. Tradução de Mário Laranjeira. São Paulo: Secretaria de Estado da Cultura/ Editora Brasiliense, 1990.

Sade, Fourier, Loyola. Tradução de Mário Laranjeira. São Paulo: WMF Martins Fontes, 2005. 
Le Plaisir du texte. Paris : Éditions du Seuil, 1973.

O Prazer do texto. Tradução de J. Guinsburg. São Paulo: Editora Perspectiva, 2006 (1977).

Où/ ou va la littérature? Entrevista com Maurice Nadeau, publicada em Écrire... pourquoi? pour qui ? Grenoble : Presses Universitaires de Grenoble, 1974. (Para o programa « Dialogues» de R. Pillaudin, France-Culture, 13 de março de 1974).

O que é a literatura. Entrevista com Roland Barthes. Tradução de Nestor de Sousa e Irineu Garcia. Rio de Janeiro: Salvat Editora, 1979.

Roland Barthes. Paris : Éditions du Seuil, 1975.

Roland Barthes. Tradução de Leyla Perrone-Moisés. São Paulo : Cultrix, 1977.

Roland Barthes. Tradução de Leyla Perrone-Moisés. São Paulo: Estação Liberdade, 2003.

Fragments d'un discours amoureux. Paris: Éditions du Seuil, 1977.

Fragmentos de um discurso amoroso. Tradução de Hortênsia dos Santos. Rio de Janeiro: F. Alves, 1981.

Fragmentos de um discurso amoroso. Tradução de Márcia Valéria Martinez de Aguiar. São Paulo: WMF Martins Fontes, 2003.

Poétique du récit (em colaboração). Paris : Éditions du Seuil, 1977. 
Leçon. Paris : Éditions du Seuil, 1978.

Aula. Tradução e posfácio de Leyla Perrone-Moisés. São Paulo: Cultrix, 2007 (1980).

Sollers écrivain. Paris : Éditions du Seuil, 1979.

Sollers escritor. Tradução de Lígia Maria Ponde Vassallo. Rio de Janeiro: Tempo Brasileiro, Fortaleza: Universidade Federal do Ceará, 1982.

La Chambre claire. Note sur la photographie. Paris : Éditions de l’Étoile/ Gallimard/ Seuil, 1980.

A Câmara clara. Nota sobre a fotografia. Tradução de Júlio Castanon Guimarães. Rio de Janeiro: Nova Fronteira, 1984.

Le Grain de la voix. Entretiens (1962-1980). Paris : Éditions du Seuil, 1981.

O Grão da voz. Tradução de Anamaria Skinner. Rio de Janeiro: Francisco Alves, 1995.

O Grão da voz. Entrevistas (1962-1980). Tradução de Mário Laranjeira, revisão da tradução de Lígia Fonseca Ferreira. São Paulo: WMF Martins Fontes, 2004.

Essais critiques III. L'Obvie et l'obtus. Paris : Éditions du Seuil, 1992 (1982).

O Óbvio e o obtuso. Ensaios críticos III. Tradução de Léa Novaes. Rio de Janeiro: Nova Fronteira, 2004 (1990). 
Essais critiques IV. Le Bruissement de la langue. Paris : Éditions du Seuil, 1993 (1984).

O Rumor da língua. Tradução de Mário Laranjeira. São Paulo: Editora Brasiliense, 1988.

O Rumor da língua. Tradução de Mário Laranjeira, revisão da tradução de Andréa Stahel M. da Silva. São Paulo: WMF Martins Fontes, 2004.

L'Aventure sémiologique. Paris : Éditions du Seuil, 1985.

A Aventura semiológica. Tradução de Mário Laranjeira. São Paulo: Martins Fontes, 2001.

Incidents. Paris : Éditions du Seuil, 1987.

Incidentes. Tradução de Júlio Castanon Guimarães. Rio de Janeiro: Editora Guanabara, 1988.

Incidentes. Tradução de Mário Laranjeira. São Paulo: WMF Martins Fontes, 2004.

Euvres complètes. Édition préparée par Éric Marty. Paris : Éditions du Seuil, 1993 (v. 1, 1942-1965), 1994 (v. 2, 1966-1973), 1995 (v. 3, 1974-1980).

Euvres complètes. Nouvelle édition revue, corrigée et présentée par Éric Marty. Paris : Éditions du Seuil, 2002, 5v.

Inéditos, I: teoria. Organização: Leyla Perrone-Moisés. Tradução: Ivone Castilho Benedetti. São Paulo: WMF Martins Fontes, 2004. 
Inéditos, II: crítica. Organização: Leyla Perrone-Moisés. Tradução: Ivone Castilho Benedetti. São Paulo: WMF Martins Fontes, 2004.

Inéditos, III: imagem e moda. Organização: Leyla Perrone-Moisés. Tradução: Ivone Castilho Benedetti. São Paulo: WMF Martins Fontes, 2005.

Inéditos, IV: política. Organização: Leyla Perrone-Moisés. Tradução: Ivone Castilho Benedetti. São Paulo: WMF Martins Fontes, 2005.

Comment vivre ensemble. Simulations romanesques de quelques espaces quotidiens. Cours et séminaires au Collège de France 1976-1977. Paris : Éditions du Seuil, 2002.

Como viver junto. Simulações romanescas de alguns espaços cotidianos. Cursos e seminários no Collège de France 1976-1977. Tradução de Leyla Perrone-Moisés. São Paulo: WMF Martins Fontes, 2003.

Le Neutre. Cours et séminaires au Collège de France 1977-1978. Paris : Éditions du Seuil, 2002.

O Neutro. Anotações de aulas e seminários ministrados no Collège de France 1977-1978. Tradução de Ivone Castilho Benedetti. São Paulo: WMF Martins Fontes, 2003.

Écrits sur le théâtre. Textes présentés et réunis par Jean-Loup Rivière. Paris : Éditions du Seuil, 2002.

Escritos sobre teatro. Tradução de Mário Laranjeira, revisão da tradução de Andréa Stahel M. da Silva. São Paulo: WMF Martins Fontes, 2007. 
La Préparation du roman I et II. Cours et séminaires au Collège de France (1978-1979 et 1979-1980). Paris : Éditions du Seuil, 2003.

A Preparação do romance I - Da vida à obra. Notas de cursos e seminários no Collège de France, 1978-1979. Tradução de Leyla Perrone-Moisés. São Paulo: WMF Martins Fontes, 2005.

A Preparação do romance II - A obra como Vontade. Notas de curso no Collège de France 1979-1980. Tradução de Leyla Perrone-Moisés. São Paulo: WMF Martins Fontes, 2005.

Journal de deuil. 26 octobre 1977-15 septembre 1979. Texte établi et annoté par Nathalie Léger. Paris : Éditions du Seuil/ IMEC, 2009.

Diário de luto. 26 de outubro de 1977-15 de setembro de 1979. Tradução de Leyla Perrone-Moisés. São Paulo: WMF Martins Fontes, 2011.

Carnets $d u$ voyage en Chine. Édition établie, présentée et annotée par Anne Herschberg Pierrot. Paris : Christian Bourgois Éditeur/ IMEC, 2009.

Cadernos da viagem à China. Tradução de Ivone Castilho Benedetti. São Paulo: WMF Martins Fontes, 2012. 